\title{
ICU-delirium assessed by CAM-ICU and validated
}

\section{by interview}

Helle Svenningsen, Critical Care Nurse, Master of Clinical Nursing, Clinical Nurse Specialist, Department of Anesthesia and Intensive Care Medicine, Aarhus University Hospital, Aarhus, Denmark

Key Words: CAM-ICU * delirium * intensive care * interview * nursing assessment *

E-mail: hellsven@rm.dk

\section{ESPAÑOL}

Evaluación del delirio en la $\mathrm{UCl}$ por medio del $\mathrm{MEC}-\mathrm{UCI}$, validación por medio de entrevista

\section{Palabras clave}

Cuidado intensivo, delirio, entrevista, evaluación de enfermería, MEC-UCI [CAM-ICU]

Resumen

El objetivo de este estudio fue traducir el Método de Evaluación de la Confusión en la Unidad de Cuidado Intensivo (MEC-UCl) al danés y utilizarlo en la práctica clínica para identificar el delirio. Además, los pacientes evaluados por el MEC-UCl fueron entrevistados después del alta del hospital para validar la herramienta utilizando una entrevista cualitativa semi-estructurada.

Pacientes adultos en tres unidades de cuidado intensivo fueron evaluados 48 horas después de la admisión en la unidad de cuidado intensivo y luego dos veces al día hasta el alta. Se excluyeron pacientes con lesiones del sistema nervioso central, psicosis al ingreso y pacientes que no hablaban danés. El autor, quien no tenía conocimiento de los valores del MEC-UCI, entrevistó diez pacientes. A continuación de la transcripción de las entrevistas se realizó un análisis de contenido.

Cuatro pacientes fueron evaluados por el MEC-UCl en estado de delirio, se confirmó por la entrevista después del alta de cuidado intensivo que todos lo habían experimentado. Seis pacientes evaluados según el método no tenían delirio; cuatro de estos pacientes no habían experimentado delirio, pero en dos casos los pacientes dijeron haberlo experimentado.

Se concluye que el MEC-UCI identifica el delirio, pero los resultados falsos negativos son posibles. Aunque este es un estudio pequeño, se concluye que el MEC-UCl es válido y puede utilizarse en estudios de intervención.

\section{SUMMARY}

- The aim of this study was to translate the Confusion Assessment Method for the Intensive Care Unit (CAM-ICU) into Danish and then to use it in clinical practice in order to identify delirium. Additionally, patients tested with the CAMICU were interviewed after discharge from hospital in order to validate the tool using semi-structured qualitative interviews.

- $\quad$ Adult patients in three intensive care units were scored 48 hours after admission to the intensive care unit and then twice a day until discharge. Excluded were patients with central nervous system injuries, psychoses at admission or nonDanish-speaking. The author, who was blinded for the CAMICU scores, interviewed ten patients. Following transcription the interviews were content analysed.

- Four patients were scored by the CAM-ICU to have delirium, and it was confirmed at interview following discharge from intensive care they had all experienced delirium. Six patients were scored negative to delirium; four of these had not experienced delirium but in two cases the patients stated that they had experienced delirium.

- It is concluded that the CAM-ICU identifies delirium, but false negative results are possible. Although only a small study, it is concluded that the CAM-ICU is valid and can be used in intervention studies.

\section{INTRODUCTION}

Delirium in critically ill patients has been recognised for more than fifty years. Several different names have been used for the syndrome, but changes in cognition, disturbances of consciousness and fluctuation in the severity of these symptoms during the day are accepted characteristics. Delirium develops over hours to days (American Psychiatric Association, 1999) and is a common problem in intensive care units (ICUs) with an incidence of 16 to $87 \%$ (Bergeron et al. 2001; Dubois et al., 2001; Ely, Gautam et al., 2001; Ely, Margoli et al., 2001; Ely, Siegel, \& Inouye 2001; Lin et al., 2004; Roberts, 2004). Symptoms differ between patients and there are three sub-types. Hyperactive delirium is characterised by agitation and easily identified. Hypoactive delirium, also called 'quiet delirium' has an incidence of up to $94 \%$ (Dubois et al., 2001; Ely, Gautam et al., 2001; Lin et al., 2004). The third sub-type is a combination of hyper- and hypoactive delirium (Hanley, 2004). Because the symptoms of delirium can fluctuate during the day it can be very difficult to identify it in a patient (Schuurmans et al., 2003).

Increased length of hospital stay, increased physical and especially mental stress and higher mortality are mentioned as complications of delirium (Dubois et al., 2001; Ely et al., 2004; Ely, Gautam et al., 2001; Lin et al., 2004; Milbrandt et al., 2004; Thomason et al., 2005). Anxiety, despair, isolation and the struggle to escape from the 'bizarre world' have been described in qualitative studies and 
by patients themselves (Laitinen, 1996; Axell, 2001; Richman, 2000; Hewitt, 2002).

\section{The Confusion Assessment Method of the Intensive Care Unit}

When considering the fact that most ICU patients are mechanically ventilated and therefore not able to participate in tests that require verbal communication, the need for a diagnostic tool for delirium in ICU patients is apparent. Within the last five years various tools have been developed internationally (Schuurmans et al., 2003), but none of these have been translated into Danish. The Confusion Assessment Method of the Intensive Care Unit (CAM-ICU) has gained favour in several countries (Ely, 2007) and is therefore a suitable subject for international comparison. The CAM-ICU has four features: 1) an acute onset of mental status changes or a fluctuating course; 2) inattention; 3) disorganised thinking; and 4) an altered level of consciousness. To be diagnosed as delirious, the patient must have both features 1 and 2 and either feature 3 or 4 .

The original validation of the CAM-ICU was performed in a prospective cohort study with 38 adult patients admitted to ICUs. Two study nurses carried out daily ratings using CAM-ICU, and an intensivist, were compared with ratings undertaken by a delirium expert using the delirium standard from the Diagnostic and Statistical Manual of Mental Disorders (fourth edition). The reliability was 95 to $100 \%$ and validity 89 to $93 \%$ of the CAM-ICU in this study (Ely, Margolin et al., 2001). Another study with 111 enrolled patients (Ely, Siegel, \& Inouye, 2001) further validated CAM-ICU and showed the tool to be suitable for use for both clinical and research purposes. After translation into Chinese, Lin et al. (2004), in a prospective cohort study with 109 enrolled patients, demonstrated the interrater reliability was 0.91 when CAM-ICU was compared with the Diagnostic and Statistical Manual of Mental Disorders.

Common features of these studies are that the researchers used another assessment instruments as a gold standard when undertaking the validation. In no cases were the patients asked if they had experienced delirium.

\section{AIM}

To investigate the correlation between assessed and experienced delirium, the aim of this study was 1 ) to translate CAM-ICU into Danish and 2) to validate the CAM-ICU using patient statements obtained by qualitative semi-structured interviews. Systematic analysis enabled the documentation of possible relationships between assessed and experienced delirium, where this was shown to exist.

\section{METHODS}

This validation study was constructed as recommended by the Northern Nurses Federation, and approved by both the Ethics Committee of Aarhus and the Danish Data Protection Agency.

The entire CAM-ICU manual (2005 version) was translated into Danish doublet and back translated twice. The author and a teacher of Medical-English undertook the translation. Two native Englishspeakers (an English-born professional translator and an Americanborn medical student) then back-translated it. Finally, consensus was reached (Hall et al., 2003).

The study group consisted of patients admitted to three ICUs (two at university hospital and one at a county hospital) from September 2005 until March 2006. Excluded were patients under 18 years, those with central nervous system injuries or psychoses at admission and those who did not speak Danish.

\section{Delirium assessment}

About 200 nurses from the three ICUs were instructed orally and in writing in delirium by the author; and the CAM-ICU guide and worksheets were delivered (Ely, 2007). A coordinator was selected at each of three ICUs to enable blinding of the author and to recruit patients. Patients were initially scored 48 hours after admission and then twice a day until ICU discharge or death. Most of the excluded patients $(n=657)$ had an ICU stay of less than 48 hours. Additionally, approximately ninety patients who were eligible for inclusion were not recruited for reasons related to heavy workload, the use of temporary staff or forgetfulness on the part of the nursing staff. It was not possible to subsequently identify these patients due to the blind nature of the study.

Of the patients included, screening was not completed in 56 cases. Most of these were too heavy sedated to be scored, some were transferred to other hospitals and eighteen died before sedation was discontinued. Patients were included as delirium-positive when one CAM-ICU assessment was positive.

\section{Interview}

A semi-structured interview guide was formulated focusing on the indicators of delirium: affected perception, hallucinations, anxiety, loneliness and surreal experiences (see table 1). Thirteen patients were randomly selected for interview by the coordinators. The baseline was to ask the first admitted included patient every month. Two died before interviews were possible and one patient did not wish to participate in the study. Of those interviewed, eight had already been transferred to the ward and two interviews were carried out on the patients' final day in the ICU. Before interview, the patients were informed orally and in writing about the project and the voluntary nature of the interview, and written consent was obtained.

The author, who was blinded to the CAM-ICU scores, interviewed patients at 0 to 3 days after discharge from the ICUs. Following transcription the interviews were content analysed (Hall, 2005; Polit \& Beck, 2006) to ensure the depth of the qualitative element and the structure at the same time.

\begin{tabular}{|l|l|}
\hline $\begin{array}{l}\text { Research questions - patients' } \\
\text { experiences of: }\end{array}$ & Interview questions \\
\hline Sensory perception & $\begin{array}{l}\text { What did you experience during your } \\
\text { stay in the ICU? }\end{array}$ \\
\hline Consciousness & Did you know were you were? \\
\hline Perception of time & $\begin{array}{l}\text { How did you experience the passage } \\
\text { of time? }\end{array}$ \\
\hline Dreams/hallucinations & $\begin{array}{l}\text { Did you dream while you were in the } \\
\text { ICU? } \\
\text { Even when you were awake? }\end{array}$ \\
\hline Unreal /real & $\begin{array}{l}\text { Did you have any experiences, that } \\
\text { you now know were imagined or } \\
\text { hallucinations? } \\
\text { Could you separate dreams from } \\
\text { reality? }\end{array}$ \\
\hline Fear & Did you feel afraid/ fear? \\
\hline Loneliness & Did you feel isolated/alone? How? \\
\hline Loss of dignity/abnormal \\
behaviour & $\begin{array}{l}\text { Did you behave in a way you now } \\
\text { know to be inappropriate? }\end{array}$ \\
\hline & $\begin{array}{l}\text { Is there any thing else you wish to } \\
\text { tell me? }\end{array}$ \\
\hline
\end{tabular}

Table 1: Interview guide

\section{RESULTS}

A total of 139 patients (65 women, 74 men) were included for CAM-ICU scoring. Their mean age was 63.6 years (range 18-88 years). Of the included 139 patients, $31(22.3 \%)$ died during the ICU admission. Thirteen patients were asked for interview, two died 
before interviews were possible, one did not wish to particiาpate. The author interviewed ten patients; eight women and two men. The mean age in the interview-group was 56.3 years $(39-66)$, and the length of stay in the ICU was from 5 to 103 days with a mean of 22.5 days.

The patients willingly related their experiences in the ICU - although four of those who had experienced delirium found the interview distressing. The interview situation was an opportunity for them to talk about the frightening world they had been in during the delirium. In the following, short extracts from the transcripts will be quoted according to the indicators of delirium used in the interview guide and then content analysed.

Six patients expressed affected perception and hallucinations:

"I was in Thailand, but the Queen flew me home, and she landed the plane behind the local supermarket. I heard voices - but they had no relation to anything. When I talked about a dog I saw yesterday, they just asked: 'What dog?' but I heard the barking."

Five patients experienced unexplained existential anxiety. Three of them had a fear of death in relation to the delirium. One fought so hard against the staff, believing that they were trying to kill him that he had to be sedated. A feeling of loneliness despite the presence of staff or relatives was common to patients with delirium. The inability to communicate because of intubation reinforced the feeling of loneliness. As one patient explained:

"All the time there was only me in the dream... well, my family was there - but since we could not communicate that worsened things."

When talking about unreal experiences it became clear that these patients had difficulty separating the real world from the unreal. Several days after discharge from ICU, they were still unsure which of their memories from the ICU were real or imagined.

\section{A patient's story}

One patient related the following story:

"You have to imagine a fairly surrealistic scene. There was a young, smart doctor who had come to show something or other.... He stood just like an animal trainer. And there was some kind of strange light, which moved around - later I was in Japan, hundreds of years ago - it was probably a memory of something I saw on television or something - where I was sacrificed at the end.

Now comes the worst part. I was sort of conscious, and I was convinced that everyone was trying to kill me because someone needed a lung. They sent someone to my window all the time - he stood and watched me. It was really strange - suddenly my two girls and my big son became part of it. It was like, they wanted me to take the poison, so he could have my lung, and I was hysterical and panicking.

There were bars at the front of the hospital - it was very strange and surreal. People moved around and got up and there were cats everywhere. A mechanical digger drove over me so that I was enclosed in a small space- I can't stand that and I panicked. Then my big son came and stood as if he didn't know my two girls. They were dressed like nurses and seemed not to know me. And the nurse tried desperately to get me to take that syringe - I kept squeezing it, so she couldn't do it. In the end my son persuaded me and I thought, 'Yes, we all have to die...?' - let him have my lung.

Then an ambulance came and delivered a coffin outside. I don't know if it was true - if it was some kind of role-play or if it was my messed up brain. I was completely down about having been like that, and I cried when I left here. I was really upset."

This patient was a large, strong man, who had been admitted due to a severe asthma attack.

Overall results

Of the ten interviewed patients, four were scored according to CAM-ICU as having had delirium. These four patients confirmed at interview that they had experienced delirium. Six patients were scored negative to delirium; four of these confirmed that they had not experienced delirium, but in two cases the patients stated that they had experienced delirium (see table 2).

\begin{tabular}{|c|c|c|}
\hline & Interview positive & Interview negative \\
\hline CAM-ICU positive & 4 & 0 \\
\hline CAM-ICU negative & 2 & 4 \\
\hline
\end{tabular}

Table 2: interview results compared to CAM-ICU scores.

\section{DISCUSSION}

Because of the fluctuating causes of delirium, diagnosis may be difficult. If the staff do not undertake the scoring twice a day or whenever there is a change in the mental condition of a patient, delirium may remain undetected. As the CAM-ICU (Ely, 2007) is only positive in the presence of an acute change in mental status, a fluctuating course (Feature 1) or inattention (Feature 2) (ICU Delirium and Cognitive Impairment Study, 2005), scoring may in some cases be stopped too early. This could be the reason for one of the patients scoring negative by CAM-ICU but positive by interview. She was scored to be 'her-self' (Feature 1 negative) for the first fifteen days, at which point scoring was discontinued. At interview, however, she told about experiencing another world, hallucinations and fear. She had the experience of being 'passive,' which could be a sign of hypoactive delirium. Another patient who scored negative but interviewed positive had the perception that he had attacked the staff when they tried to get near him. When the author told the staff about this, they recognised this as the period when they had to sedate the patient because he was very aggressive. However, the sedation made the CAM-ICU score unreliable and no positive scores were recorded. Had the author not been blind to the scores, this case could have been excluded. As previously stated, an absence of blinding may have reduced the number of excluded patients. However any bias resulting from the exclusion of these patients is probably random.

False negative results are present in another work. CAM-ICU was compared with the Confusion Assessment Method (CAM) (McNicoll et al., 2005) by two blinded clinicians examining twentytwo patients. Using CAM as the reference standard, the CAM-ICU had four $(18 \%)$ false negative results. The more detailed cognitive testing of the CAM was explained as the reason for three of these instances (McNicoll et al., 2005). This illustrates the need for tests to be sufficiently detailed. Likewise it must be reasonable to explore the whole period of hospitalisation, and not just the first few days (Lin et al., 2005) according to the fluctuation cause of delirium and the uncertainty about when delirium occurs (Axell 2001; Ely, Gautam et al., 2001; Ely, Siegel, \& Inouye 2001). As the diagnosis of delirium becomes more accurate, it is to be expected that a greater number of occurrences of delirium will be identified.

Poldeman (2007) mention the possibility of false-positive results using CAM-ICU compared to the lower incidence shown by the Intensive Care Delirium Screening Checklist (ICDSC) (Bergeron er al., 2001; Ouimet et al., 2007), however in the present study, as well as in earlier ones (Ely, Margolin et al., 2001b; Ely, Siegel, \& 
Inouye 2001; Lin et al., 2004), there is an absence of false positive results in the validation of CAM-ICU. This is an important result due to the severe side-effects of Haloperidol (prolonged QT interval, paralytic ileus, extrapyramidal disease, hypotension among others) which is recommended treatment for delirium (American Psychiatric Association, 1999).

Treatments for delirium are still not clearly defined, and the complex clinical situation of most ICU patients makes prevention or treatment of the delirium difficult (Querques, 2006). It is probably impossible to identify any simple means of preventing or treating ICU delirium. However, some measures have been suggested, such as modifying the systemic inflammatory response (Hala, 2007), ensuring normal haemoglobin levels (Axell, 2001; Joosten et al., 2006) and natural sleep (Hewitt, 2002; Pandharipande \& Ely, 2006), avoiding medications such as meperidine (Fong et al., 2006), midazolam (Axell, 2001; Pandharipande \& Ely, 2006) and fentanyl, but at the same time preventing severe pain (Fong et al., 2006; Vaurio et al., 2006). Nevertheless, certain measures are generally accepted: reducing environmental noise, early mobilisation, optimising visual and aural acuity, sleep protocols, correcting dehydration, minimising pain, facilitating the patient's orientation and the presence of relatives are presumed to reduce delirium (Casarett \& Inouye, 2001; Truman \& Ely, 2003). Where it is not possible to prevent delirium, both patient and relatives can probably have benefit from a follow-up service at the end of the hospital stay or after discharge from ICU. In the event of long-term cognitive impairment, and in some cases even dementia, that many post-delirious (and even non-delirious patients) suffer from (Jackson et al., 2004; Jones et al., 2006; Nelson et al., 2006) an opportunity to understand their experiences during the delirium will extend ( Roberts et al., 2006; Pattison et al., 2007).

Delirium is a complex phenomenon with possibly severe consequences for affected patients such as prolonged hospital stay, reduced quality of life or even mortality (Milbrandt et al., 2004; Granja et al., 2005; Jackson et al., 2004; Thomason et al., 2005; Jones et al., 2006; Meyer \& Hall, 2006; Nelson et al., 2006; Roberts et al., 2006; Ouimet et al., 2007), which requires further investigation. In this study, CAM-ICU has been validated using qualitative interviews, and aggregated with the other validation studies (Ely, Margolin et al., 2001; Ely, Siegel, \& Inouye, 2001; Lin et al., 2004; McNicoll et al., 2005 ) it appears to be a possible tool for use in intervention studies of the nature of delirium.

\section{ACKNOWLEDGEMENTS}

The author thanks the Novo Nordic Foundation for financial and independent support; Professor Else Tønnesen, Århus University Hospital for her helpful review; RN Nick Faddy, Århus University Hospital for his linguistic revision of this manuscript, and all the staff from the ICUs of Ârhus University Hospital THG, NBG and Sygehus Viborg.

\section{REFERENCES}

American Psychiatric Association (1999). Practice Guideline for the Treatment of Patients with Delirium. [Online.] Available at: http:// www.psychiatryonline.com/pracGuide/PracticePDFs/Delirium_ Inactivated_04-16-09.pdf

Axell AG (2001). The Intensive Care Unit Syndrome/Delirium, Patients' Perspective and Clinical Signs. Dissertation/Thesis: Medicinsk Fakultet, Lunds Universitet.

Bergeron N, Dubois MJ, Dumont M, Dial S, Skrobik Y (2001). Intensive care delirium screening checklist: evaluation of a new screening tool. Intensive Care Medicine 27 (5), 859-864.

Casarett DJ, Inouye SK (2001). Diagnosis and management of delirium near the end of life. Annals of Internal Medicine 135 (1), 32-40.

Dubois MJ, Bergeron N, Dumont M, Dial S, Skrobik Y (2001). Delirium in an intensive care unit: a study of risk factors. Intensive Care Medicine 27 (8), 1297-1304.

Ely EW (2007). The Confusion Assessment Method for the ICU (CAM-ICU): Training Manual. [Online.] Available at: http://www. icudelirium.org/docs/CAM_ICU_training.pdf

Ely EW, Gautam S, Margolin R, Francis J, May L, Speroff T, Truman B, Dittus R, Bernard R, Inouye SK (2001). The impact of delirium in the intensive care unit on hospital length of stay. Intensive Care Medicine 27 (12), 1892-1900.

Ely EW, Margolin R, Francis J, May L, Truman B, Dittus R, Speroff T, Gautam S, Bernard GR, Inouye SK (2001). Evaluation of delirium in critically ill patients: validation of the Confusion Assessment Method for the Intensive Care Unit (CAM-ICU). Critical Care Medicine 29 (7), 1370-1379.

Ely EW, Shintani A, Truman B, Speroff T, Gordon SM, Harrell FE Jr, Inouye SK, Bernard GR, Dittus RS (2004). Delirium as a predictor of mortality in mechanically ventilated patients in the intensive care unit. JAMA 291 (14), 1753-1762.

Ely EW, Siegel MD, Inouye SK (2001). Delirium in mechanically ventilated patients: validity and reliability of the Confusion Assessment Method for the Intensive Care Unit (CAM-ICU). JAMA 286 (21), 2703-2710.

Fong HK, Sands LP, Leung JM (2006). The role of postoperative analgesia in delirium and cognitive decline in elderly patients: a systematic review. Anesthesia and Analgesia 102 (4), 1255-1266.

Granja C, Lopes A, Moreira S, Dias C, Costa-Pereira A, Carneiro A (2005). Patients' recollections of experiences in the intensive care unit may affect their quality of life. Critical Care 9 (2), R96-R109.

Hala M (2007). Pathophysiology of postoperative delirium: systemic inflammation as a response to surgical trauma causes diffuse microcirculatory impairment. Medical Hypotheses 68 (1), 194196.

Hall EO (2005). Danish parents' experiences when their new born or critically ill small child is transferred to the PICU - a qualitative study. Nursing in Critical Care 10 (2), 90-97.

Hall EO, Wilson ME, Frankenfield JA (2003). Translation and restandardisation of an instrument: the Early Infant Temperament Questionnaire. Journal of Advanced Nursing 42 (2), 159-168.

Hanley C (2004). Delirium in the acute care setting. MEDSURG Nursing 13 (4), 217-225.

Hewitt J (2002). Psycho-affective disorder in intensive care units: a review. Journal of Clinical Nursing 11 (5), 575-584.

ICU Delirium and Cognitive Impairment Study Group (2005). CAMICU Training Manual: Frequently Asked Qiuestions. [Online.] Available at: http://www.icudelirium.org/docs/CAM_ICU_FAQs.pdf

Jackson JC, Gordon SM, Hart RP, Hopkins RO, Ely EW (2004). The association between delirium and cognitive decline: a review of the empirical literature. Neuropsychology Review 14 (2), 87-98.

Jones C, Griffiths RD, Slater T, Benjamin KS, Wilson S (2006). Significant cognitive dysfunction in non-delirious patients identified during and persisting following critical illness. Intensive Care Medicine 32 (6), 923-926.

Joosten E, Lemiengre J, Nelis T, Verbeke G, Milisen K (2006). Is anaemia a risk factor for delirium in an acute geriatric population? Gerontology 52 (6), 382-385.

Laitinen H (1996). Patients' experience of confusion in the intensive care unit following cardiac surgery. Intensive and Critical Care Nursing 12 (2), 79-83. 
Lin SM, Liu CY, Wang CH, Lin HC, Huang CD, Huang PY, Fang YF, Shieh MH, Kuo HP (2004). The impact of delirium on the survival of mechanically ventilated patients. Critical Care Medicine 32 (11), 2254-2259.

McNicoll L, Pisani MA, Ely EW, Gifford D, Inouye SK (2005). Detection of delirium in the intensive care unit: comparison of Confusion Assessment Method for the Intensive Care Unit with Confusion Assessment Method ratings. Journal of the American Geriatrics Society 53 (3), 495-500.

Meyer NJ, Hall JB (2006). Brain dysfunction in critically ill patients the intensive care unit and beyond. Critical Care 10 (4), 223.

Micek ST, Anand NJ, Laible BR, Shannon WD, Kollef MH (2005). Delirium as detected by the CAM-ICU predict restraint use among mechanically ventilated medical patients. Critical Care Medicine 33 (6), 1260-1265.

Milbrandt EB, Deppen S, Harrison PL, Shintani AK, Speroff T, Stiles RA, Truman B, Bernard GR, Dittus RS, Ely EW (2004). Costs associated with delirium in mechanically ventilated patients. Critical Care Medicine 32 (4), 955-962.

Nelson JE, Tandon N, Mercado AF, Camhi SL, Ely EW, Morrison RS (2006). Brain dysfunction: another burden for the chronically critically ill. Archives of Internal Medicine 166 (18), 1993-1999.

Ouimet S, Kavanagh BP, Gottfried SB, Skrobik Y (2007). Incidence, risk factors and consequences of ICU delirium. Intensive Care Medicine 33 (1), 66-73.

Pandharipande P, Ely EW (2006). Sedative and analgesic medications: risk factors for delirium and sleep disturbances in the critically ill. Critical Care Clinics 22 (2), 313-27, vii.

Pattison NA, Dolan S, Townsend P, Townsend R (2007). After critical care: a study to explore patients' experiences of a followup service. Journal of Clinical Nursing 16 (11), 2122-2131.
Polderman KH (2007). Screening methods for delirium: don't get confused! Intensive Care Medicine 33 (1), 3-5.

Polit DF, Beck CT (2006). Essentials of Nursing Research: Methods, Appraisal, and Utilisation, 6th edition. Philadelphia: Lippincott Williams \& Wilkins.

Querques J (2006). Disordered consciousness: delirium in the intensive care unit. Seminars in Anesthesia, Perioperative Medicine and Pain 25 (4), 219-224.

Richman J (2000). Coming out of intensive care crazy: dreams of affliction. Qualitative Health Research 10 (1), 84-102.

Roberts B (2004). Screening for delirium in an adult intensive care unit. Intensive and Critical Care Nursing 20 (4), 206-213.

Roberts BL, Rickard CM, Rajbhandari D, Reynolds P (2006). Patients' dreams in ICU: recall at two years post discharge and comparison to delirium status during ICU admission. A multicentre cohort study. Intensive and Critical Care Nursing 22 (5), 264-273.

Schuurmans MJ, Deschamps PI, Markham SW, Shortridge-Baggett LM, Duursma SA (2003). The measurement of delirium: review of scales. Research in Nursing and Health 17 (3), 207-224.

Thomason JWW, Shintani A, Peterson JF, Pun BT, Jackson JC, Ely EW (2005). Intensive care unit delirium is an independent predictor of longer hospital stay: a prospective analysis of 261 non-ventilated patients. Critical Care 9 (4), R375-R381.

Truman B, Ely EW (2003). Monitoring delirium in critically ill patients. Intensive and Critical Care Nursing 23 (2), 25-38.

Vaurio LE, Sands LP, Wang Y, Mullen EA, Leung JM (2006). Postoperative delirium: the importance of pain and pain management. Anesthesia and Analgesia 102 (40, 1267-1273. 